\title{
Feito com mais de mil pedaços
}

\author{
Regina Petrus *
}

Fui visitar, há poucos dias ${ }^{1}$, um grupo de jovens refugiados, moradores da primeira Casa de Acolhida para Refugiados no Rio de Janeiro. A casa foi inaugurada em 2005 e está situada no bairro de Brás de Pina, em localidade conhecida como Quitungo. Não fica propriamente dentro da favela que tem esse nome, mas logo no início de uma das ladeiras que dão acesso à "comunidade". Assim explicou o rapaz que cuida da casa quando, já autorizada e confirmada a visita, orientou-me pelo telefone.

A visita à casa de acolhida foi precedida de muita expectativa de minha parte. Há quase dez anos tenho como objeto de estudo e de pesquisas grupos de estrangeiros que vieram para o Rio de Janeiro em busca de refúgio. Pelo fato de pesquisar a problemática do refúgio e de conviver com muitos desses emigrantes-imigrantes-refugiados por tanto tempo, sei que a questão da moradia é fundamental para quem chega a um país estranho, fugindo de sua terra natal, muitas vezes sem recurso algum e ainda sem contar com o apoio de redes sociais. Conseguir um lugar para morar é um grande problema a ser enfrentado pelos refugiados. Por isso, percebi a criação de uma casa de acolhida para refugiados como um projeto de grande importância que, sem dúvida, já chegara com atraso diante da realidade do refúgio no Rio de Janeiro. Projeto este que vem enfrentando dificuldades para se consolidar, mas que precisa e deve ser valorizado e apoiado com recursos de diversas fontes.

A novidade da visita à casa acendeu uma vez mais meu desejo de pesquisadora. Especialmente porque os objetivos e a questão central da minha pesquisa atual levaram-me a eleger, dentre os diversos grupos e subgrupos de refugiados recentes, os refugiados congoleses como sujeitos centrais na trama de discursos sobre a integração de refugiados no Rio de Janeiro - o que pretendo estudar.

* Prof a do CAp.UFRJ e Pesquisadora associada ao Núcleo Interdisciplinar de Estudos Migratórios - NIEM/UFRJ. 


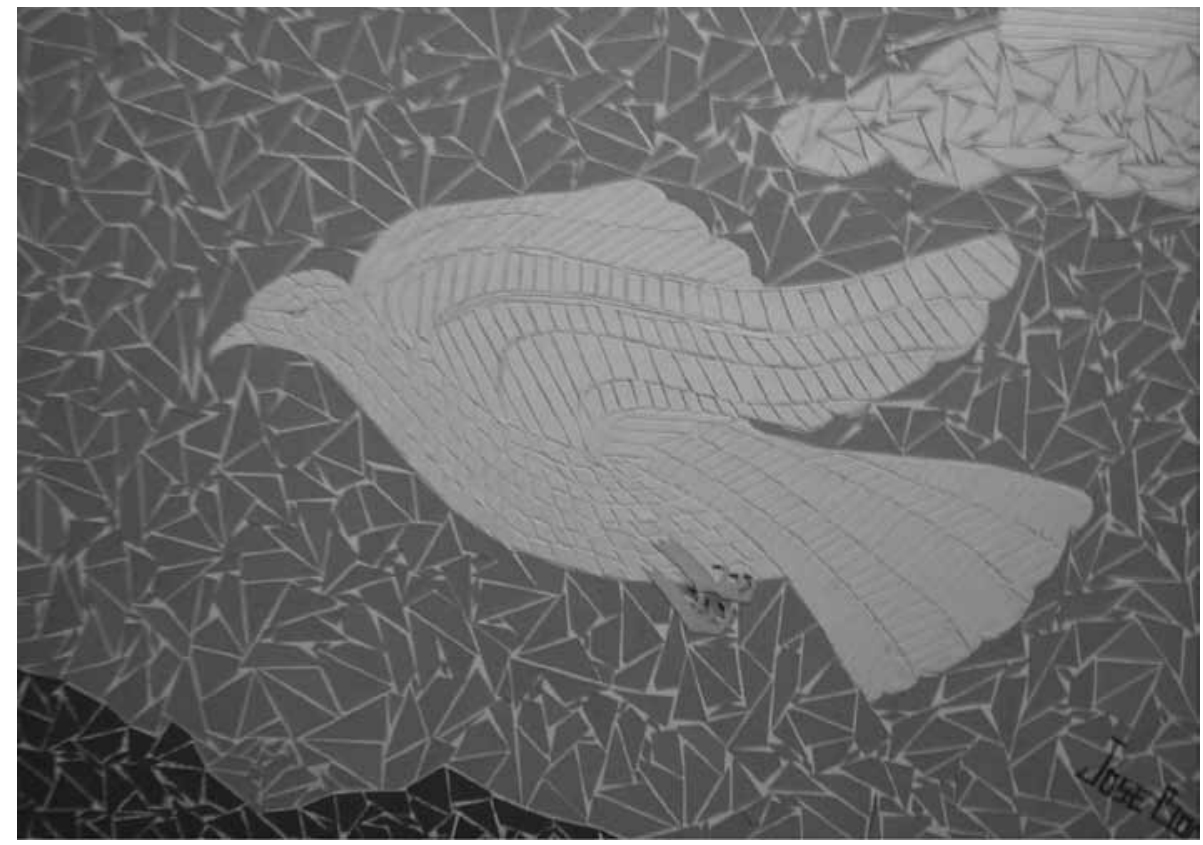

Visita agendada e confirmada. Cheguei ao local numa quarta-feira, no meio da manhã. Na porta, já à espera, estavam as duas assistentes sociais que coordenam o projeto. Acionei imediatamente meu "olhar de pesquisadora" ao grau máximo de capacidade de observação - pelo menos ao maior grau possível naquela circunstância, em que, objetividade/racionalidade e desejo/emoção se misturavam em mim de maneira inextricável.

Entramos na casa por um portão com grades altas e passamos por um pequeno corredor - também com grades - que separam "a casa" do quintal de uma creche mantida para as crianças da "comunidade", pela Paróquia de Santo Antonio do Quitungo.

Meu lado nada racional já ia reagindo ao "cercamento" da casa, mas imediatamente pensei que a presença das grades ali era inevitável para uma sensação de proteção.

Imediatamente, um cheiro tentador de feijão cozinhando entrou pelo meu nariz - agradando os sentidos e amenizando a tensão.

$\mathrm{Na}$ cozinha - primeiro lugar da casa que conheci - estava um jovem alto, negro, bonito, em suas plenas funções de "cozinheiro da semana" - como me foi explicado - picando temperos com esmero, em pedacinhos bem pequenos que ia jogando aos poucos na panela. Como em um programa de TV. A postura altiva e orgulhosa dos africanos - que permanece com eles onde quer que estejam e que tanto aprendi a admirar e compreender em meu trabalho e convívio com os refugiados angolanos - me fez sorrir internamente. O imponente cozinheiro chama-se João. É esse o seu nome no Brasil. 
João cumprimentou-nos com um "olá" meio sem jeito, um aceno de cabeça, e voltou a picar seus pedacinhos. Logo chegaram as outras profissionais que prestam serviços especializados na casa de acolhida: uma psicóloga, uma professora de artes e uma advogada.

Do corredor surgiram mais dois refugiados bem jovens, também negros, também africanos. A psicóloga conduziu as apresentações.

Vista a cozinha e o refugiado cozinhando - e já feita a apresentação geral - fui encaminhada para o interior da casa, onde tudo estava perfeitamente arrumado e preparado para a visita. A limpeza impecável da cozinha já havia chamado minha atenção. Mas o mesmo padrão de organização e cuidado estava presente por toda a casa.

Nos quartos não havia nada à vista além dos móveis, ou melhor, das camas-beliche. Todas elas etiquetadas com números de um a vinte, e impecavelmente arrumadas. Nem roupas, nem quadros, nem sapatos, nem fotos. Nenhum objeto pessoal, nenhuma marca individual se via por ali. Porém, ao olhar para um canto de um dos quartos, surpreendi-me com um violão encostado ao lado de uma das camas. Neste mesmo quarto havia ainda uma mesinha com uma cadeira. Na verdade, o lugar preferido para escrever cartas para os que ficaram (...) mandar notícias (...) estudar e treinar a nova língua que precisam aprender.

Conforme me foi explicado pela assistente social, na "casa de acolhida temporária" há um rodízio não só para as tarefas, mas também para o uso dos armários, das camas, dos quartos e da única mesinha com cadeira que vi em um deles. Afirmou que sabia o quanto era difícil a situação como um todo, mas ressaltou:

"Eles precisam internalizar que na casa tudo é de todos e ninguém deve se sentir dono individualmente de nada".

Trata-se de uma casa de acolhida - como já expliquei. E acolhe. Mas tanta falta de rastros, pertences ou marcas das diferentes pessoas que a habitam, causaram-me uma estranha sensação de vazio. Respirei fundo para sentir mais forte o cheiro do feijão cozinhando e, então, fui conhecer os banheiros. Comprovação absoluta do padrão de limpeza.

Todas as tarefas de manutenção e funcionamento do espaço são de responsabilidade dos próprios "moradores". Desde o feijão cheiroso até a arrumação, limpeza da casa e manutenção do que for necessário.

Já seguindo pelo corredor central, vi os armários embutidos usados pelos moradores. Bem em frente a eles, um quadro com uma escala de revezamento dos moradores para as tarefas cotidianas. A assistente social informou que havia regras a serem cumpridas para entradas e saídas, ausência por horas ou até por todo o dia, e mesmo por noites - o que também era permitido. Existiam regras, também, para o sistema em rodízio vigente para todas as tarefas, bem como horários determinados para a participação de todos nas "atividades obrigatórias" oferecidas pelas profissionais especializadas que cooperam com seu trabalho para o "projeto da casa". 
Além dessas profissionais, conheci o rapaz que confirmou a visita. Um morador da comunidade local, ligado à Paróquia, misto de gerente e zelador do funcionamento da casa, a quem, na prática, cabe lidar diariamente com os refugiados-moradores-temporários. Em uma pequena mesinha, ele me mostrou um caderno de anotações onde tudo é registrado e que serve de meio de comunicação entre todos: os moradores, as profissionais especializadas, as coordenadoras do projeto e ele (que gerencia e zela pela casa). Fui informada do limite de três advertências anotadas no caderno para que um refugiado pudesse continuar morando na "casa".

Meu lado emocional e crítico começou a questionar a disciplina rígida. Imediatamente, contudo, minhas lembranças da dificuldade em organizar minimamente $o$ trabalho que fiz durante alguns anos com os angolanos no complexo da Maré vieram temperar e amenizar minha crítica, acionando a objetividade e a racionalidade necessárias para pensar a importância das regras de convivência e conduta, em um projeto de acolhida que engloba um trabalho consistente para a integração dos refugiados em uma nova realidade sociocultural.

A psicóloga explicou que "as coisas vinham funcionando bem" porque tudo era muito bem explicado e conversado, discutido e acordado por todos (...) e também porque as regras eram muito claras, mas poderiam variar em situações específicas - desde que avaliadas com cuidado por todos os envolvidos e "dentro dos padrões gerais já estabelecidos". Dentro de mim, emoção e objetividade continuavam em conflito no campo fértil da contradição e dos paradoxos.

A casa é uma comunidade. Espaço de vida cotidiana compartilhada em seus elementos da esfera das práticas, do nível do simbólico, das diferenças entre sujeitos concretos, ainda que submetidos ali a uma mesma condição. Embora esteja localizada fora da "comunidade", ou melhor, bem no início da ladeira que dá acesso à "comunidade", a "casa" não consegue ficar alheia e absolutamente separada do seu entorno. Explico. A "comunidade" é uma das muitas favelas no Bairro de Brás de Pina. Lugar sobre o qual os refugiados-moradores-temporários são alertados para ter muito cuidado e, especialmente, evitar envolvimento com os moradores da área. A não ser com aqueles já bem conhecidos e que frequentam as atividades que a paróquia Santo Antônio do Quitungo promove. Tudo para evitar problemas para "a casa" e para eles mesmos.

Meu trajeto de deslocamento pela "casa" chegou ao ponto principal. Fui conduzida à sala. Lá estavam reunidos todos os refugiados presentes na casa naquele momento - cinco homens jovens, negros, africanos.

Além de duas mesas grandes, havia algumas estantes com diversos materiais e cadeiras já arrumadas - onde todos nos acomodamos.

Fui invadida por uma chuva de informações, falas, silêncios, imagens, olhares, emoções, experiências e realizações dos refugiados e dos profissionais da casa. Tentava não perder nada (como boa observadora que precisava ser!). Meus dois lados (razão e sensibilidade) em saudável e preservado conflito - já 
confessado a vocês leitores - agitaram-se e me deixaram em estado de alerta e expectativa total. Percebi flores sobre uma das mesas.

A psicóloga começou a falar agradecendo as flores aos refugiados-moradores e explicou: "são uma surpresa, preparada por eles para nos receber". Sorrisos discretos, mas cheios de orgulho, encheram a sala.

A assistente social que coordena o projeto tomou a palavra, fornecendo as informações oficiais gerais. Esclareceu que o projeto da casa de acolhida é parte das políticas de acolhimento e do programa para a assistência e integração dos refugiados no Brasil. A "casa" é um lugar para moradia temporária, onde os refugiados podem permanecer por um prazo que não deve exceder sessenta dias. Os "moradores da casa" são todos eles migrantes forçados que, em função de guerra civil, conflitos armados em diversas escalas territoriais e/ou por motivo de perseguição política, étnica ou religiosa em seus países de origem, tornam-se imigrantes no Brasil. Imigrantes com um estatuto jurídico especial e diferente dos demais - o de refugiado. Ser um solicitante de refúgio ou já oficialmente um refugiado Ihes garante a proteção das Nações Unidas e do governo brasileiro - porque o Brasil, além de ser um país signatário de todas as convenções, protocolos e acordos nessa área internacional dos Direitos Humanos, tem uma Lei Nacional para refugiados desde 1997.

Foi explicado também que a casa tem capacidade para acolher até vinte pessoas e que, de um total de vinte camas numeradas que "a casa" possui, cinco funcionam como uma reserva estratégica para a acolhida de casos considerados emergenciais. Aliás, emergências e situações inesperadas, de todos os tipos, fazem parte da problemática da proteção, acolhimento e integração no âmbito do refúgio. E todos os emigrantes-imigrantes-refugiados-moradores temporários sabem disso. Sabem muito bem disso, também, todos aqueles que se envolvem com a causa e o universo do refúgio, aqueles que trabalham em ações concretas junto aos refugiados.

Na sequência do roteiro preparado para a visita, a assistente social pediu que cada um dos refugiados se apresentasse e falasse alguma coisa (o que desejasse) para a "professora-visitante". Só então, ouvi as vozes e os sussurros dos moradores-temporários. E fiquei sabendo que quatro deles eram da República do Congo e um de Angola. A psicóloga explicou que os congoleses ainda estavam começando a aprender o português e tinham alguma dificuldade para falar. "Por isso alguns estão um pouco tímidos..." - reforçou.

Observei em uma das paredes da sala um quadro de avisos com a programação das atividades internas e externas da semana. Outro quadro menor, bem na minha frente, informava alguns telefones úteis como o da emergência hospitalar mais próxima e algumas linhas de ônibus com os trajetos especificados. Em destaque, aquelas linhas que levam ao local onde fica a sede Programa de Atendimento a Refugiados da Cáritas, (instituição vinculada diretamente à Igreja Católica e à Arquidiocese do Rio de Janeiro) que coordena e é a principal responsável pelo projeto da casa. Essa instituição atua em parceria com o Alto 
Comissariado das Nações Unidas para os Refugiados (ACNUR), com o CONARE e com o Governo Federal, nos diversos campos pertinentes ao âmbito do refúgio. Desde recepção e primeiras entrevistas com os solicitantes de refúgio, primeiras orientações sobre direitos e deveres, registro, documentação, assistência jurídica, bem como em várias esferas referentes ao processo de integração dos refugiados à sociedade.

É para a sede do Programa de Atendimento, situada no bairro da Tijuca, que os solicitantes de refúgio são encaminhados quando chegam à cidade. Esse local passa a ser o primeiro espaço de referência para todos os refugiados no Rio de Janeiro. Em geral, os solicitantes de refúgio e os refugiados chegados em tempos mais recentes comparecem com muita frequência à sede do programa da Cáritas; para atender a diversas exigências legais, resolver problemas em geral, receber orientação para obter seus documentos, tratar do ingresso em escolas, cursos de qualificação para o mercado de trabalho, aulas de português e outras necessidades mais prementes, além das mais variadas questões que se possa imaginar.

Voltando à casa e ao roteiro da apresentação. A psicóloga fez com que minha atenção se voltasse para outra parede da sala, onde estavam colados vários desenhos feitos pelos refugiados-moradores. Ela pediu que cada um deles mostrasse o seu desenho e explicasse o que significava. Sucessivamente, os desenhos foram apontados e "narrados" pelos seus autores: um Cristo Redentor, uma bandeira de Angola, uma casa com a fundação feita com pedras bem firmes...

Logo chegou a vez de João Boka - o congolês que estava ao meu lado e com quem eu tinha conseguido trocar algumas poucas palavras e comentários em voz baixa. Seu desenho era em tons suaves, com traços leves e bonitos que retratavam a figura de um pescador puxando uma rede cheia de peixes. Ao fundo, figuras que pareciam descansar em redes de dormir amarradas em árvores. João Boka falava baixo e lentamente, sobre o que estava pensando quando fez o desenho. Imaginação solta, memórias e lembranças no olhar, esperança no tom da voz e no ritmo da fala.

Meu coração se apertou. Mas meu escudo de pesquisadora, é claro, me faz pensar nos significados não explicitados do desenho: imagens como linguagem, memória e identidade, narrativa e posição dos sujeitos, os sentidos dos discursos falados, desenhados, dos silêncios (...). Abracei forte meu caderno de anotações de campo (e junto com ele meus conceitos tão firmes e seguros) enquanto via e ouvia os primeiros enunciados de sujeitos discursivos que compõem meu objeto de pesquisa.

João Boka - falando diretamente para mim - apontou seu nome no quadro e me deu um inesperado presente. Mostrou o nome que assinara, mas me contou que na língua falada na sua terra, seu nome era diferente e tinha outra pronúncia. Muito surpresa, tentei várias vezes repetir o nome, sem acertar. João ria de mim, achando graça no meu esforço. Sorri meio sem graça para ele, como que me desculpando, e fiz muitos elogios ao desenho. 
Quando João voltou a sentar-se ao meu lado, agradeci baixinho a confiança e o presente que me dera ao contar o seu nome de família. Sabia o valor que esta revelação tinha para ele. Percebi seus olhos um pouco molhados e imediatamente pensei em colocar meus óculos de professora. Mas me contive e lhe dirigi meu olhar e um sorriso livremente emocionados.

Seguiu-se a apresentação dos outros trabalhos. Agora, daqueles feitos nas aulas com a professora de artes. Os moradores-refugiados mostraram dois grandes quadros construídos como um mosaico de infinitos pedacinhos de papel; de muitas cores; em diversas formas triangulares; pequenas; algumas pecinhas minúsculas. Em uma das estantes estavam outros quadros de tamanho menor, feitos com a mesma técnica, paciência, perseverança, força de vontade e, certamente, em tempo demorado e necessariamente lento. A professora de artes explicou que os trabalhos menores tinham sido feitos individualmente. Os grandes, produzidos em conjunto, iriam para uma exposição.

Para finalizar a visita, a psicóloga pediu que o outro João - o do feijão buscasse seu violão para cantar uma música que estavam ensaiando. Uma canção do norte do Congo - que me pareceu um hino evangélico - cantada em algum dialeto regional. Enquanto os refugiados do Congo cantavam, as pessoas que trabalham na casa se esforçavam para acompanhá-los, cantando junto com eles algumas partes já aprendidas.

Visita encerrada. Muitos agradecimentos de minha parte, parabéns a todos pelos trabalhos, pela casa, pela música. Uma anotação de meu nome e meus contatos no caderno de registros, muitos votos de boa sorte. Numa fala final, dirigida a todos, revelo meu desejo de retornar à "casa" outras vezes: "Para podermos conversar mais" - disse eu. E expliquei que queria apresentar melhor a minha pesquisa e contar um pouco do meu trabalho, desde alguns anos atrás, com refugiados e imigrantes vindos de Angola. Contei que havia feito com os angolanos um trabalho com canções e histórias tradicionais, que se transformara em um CD. Afirmei que, se quisessem e fosse possível, poderia trazer para eles alguns CDs de cantores africanos, em várias línguas. Artistas já famosos na Europa e nos Estados Unidos. Vários deles do Congo e de Angola.

João - o cozinheiro que pica temperos em pedacinhos com tanto esmero, canta e toca violão - mostrou um sorriso e pareceu feliz com minha ideia de trazer os discos. O outro, João Boka nos desenhos, com nome ancestral tão difícil, não estava mais na sala.

Já estava eu saindo da casa em companhia das assistentes sociais da Cáritas quando João Boka apareceu. Nas mãos um dos pequenos quadros de mosaico. Que me ofereceu, esticando bem os braços. Depois, inclinou um pouco a cabeça e cruzou as mãos no peito. Sorri para ele, agradecendo. E olhei o quadro com cuidado.

Muitos e muitos pedacinhos de papel, de vários tamanhos, recortados em formas triangulares e retangulares, e colados com espantosa perfeição, formavam uma grande pomba branca da paz, voando acima das montanhas verdes, num céu azul claro onde brilhava um sol amarelo. 
O cheiro do feijão do outro João mexeu mais uma vez com meus sentidos e se juntou às cores do mosaico que João Boca me deu de presente.

Joguei fora ali mesmo na calçada meu escudo de pesquisadora.

\section{Nota}

1 - Relato extraído do diário de pesquisa de campo sobre visita à Casa de Acolhida para refugiados no Rio de Janeiro, realizada no dia 31 de agosto de 2006. 